(2) Open Access Full Text Article

\title{
Integrating Family-Based Treatment Principles in the Acute Inpatient Treatment of Adolescents with Restrictive Eating Disorders
}

This article was published in the following Dove Press journal:

Psychology Research and Behavior Management

\author{
Melissa Freizinger $\mathbb{D}^{1,2}$ \\ Grace Jhe ${ }^{1,2}$ \\ Emily Pluhar $\mathbb{D}^{1,2}$ \\ Lisa Mancini ${ }^{1}$
}

'Division of Adolescent and Young Adult Medicine, Boston Children's Hospital, Boston, MA, 021I5, USA; ${ }^{2}$ Department of Psychiatry, Harvard Medical School, Boston, MA, 02115, USA
Correspondence: Melissa Freizinger Division of Adolescent and Young Adult Medicine, Boston Children's Hospital, 333 Longwood Avenue, Boston, MA, 02115, USA

Tel +16173555974

Fax +16177300004

Email melissa.freizinger@childrens. harvard.edu

\begin{abstract}
Eating disorders (ED) are serious psychiatric illnesses with one of the highest mortality rate of any psychiatric disorder. The health sequelae of eating disorders are one of the most common causes of medical hospitalizations at freestanding pediatric hospitals in the United States. The economic impact of EDs on health systems and families is substantial. The Society for Adolescent Medicine (SAHM) recommends family-based treatment (FBT) as the first-line approach for adolescents with restrictive eating disorders due to a large body of evidence demonstrating the treatment's efficacy and cost effectiveness. Although FBT was originally developed as an outpatient treatment, the tenets and principles of the treatment have also been used in higher levels of care. This brief report discusses how components of FBT were adapted for a medical inpatient unit at a pediatric hospital in order to integrate empirically based treatment.
\end{abstract}

Keywords: eating disorders, family-based therapy, medical inpatient treatment, anorexia nervosa

\section{Introduction}

Eating disorders (EDs) have significant psychiatric and medical consequences. Restrictive EDs can lead to medical complications of malnourishment and weight loss, such as dehydration, EKG abnormalities, physiological instability, and electrolyte disturbances, that often require medical hospitalizations. ${ }^{1}$ These medical complications can be severe or even life-threatening and may compromise the functions of vital organs and systems. It is critical that these at-risk patients are medically monitored and stabilized.

The treatment approach for medical inpatients warrants attention as hospital admissions contribute to greater functional impairment and are distressing to both patient and family members. ${ }^{2,3}$ Prolonged hospital admissions are often financially and emotionally stressful for patients and families, and can disrupt normal adolescent development, school, social life, and family functioning. ${ }^{2}$

Boston Children's Hospital (BCH) is a pediatric tertiary care teaching hospital. Patients with EDs who are admitted for medical stabilization are managed by a multidisciplinary team including medical staff from Adolescent and Young Adult Medicine (AYAM), psychiatric consultation service (PCS), nutrition, and nursing. In any given year, approximately 150 patients with EDs are admitted to the medical floor with an average length of stay of 5-7 days. The primary focus of 
most inpatient admissions is medical stabilization. Throughout the inpatient stay, the treatment team works with the family to determine the appropriate discharge plan based on patient psychiatric symptoms and severity, the family's geographical location, insurance coverage, and the family's ability to engage in treatment.

Several international organizations, The Society for Adolescent Medicine (SAHM), American Psychiatric Association (APA), and the National Institute for Clinical Excellence (NICE) have recommended the inclusion of the family in ED treatment and the use of family-based treatment (FBT), an empirically based approach designed to increase parental responsibility and empowerment. ${ }^{1-6}$

Prior research has demonstrated that manualized FBT is the most effective treatment for adolescents with restrictive eating disorders. ${ }^{7}$ FBT was originally designed to be a structured time-limited outpatient treatment. Due to the growing body of research demonstrating positive treatment outcomes using FBT, clinicians and treatment programs have started to incorporate FBT tenets into higher levels of care $^{8-10}$ As a result of these recommendations and data demonstrating the clinical efficacy and cost effectiveness of $\mathrm{FBT}^{7}$ senior medical staff recommended that FBT principles be integrated into BCH's inpatient treatment protocol for patients with restrictive EDs.

The clinical and economic benefits of using FBT to treat EDs are robust in the literature. A large RCT found that FBT for anorexia nervosa (AN) was superior to adolescent-focused individual psychotherapy (AFT), resulting in less hospitalizations and lower rates of relapse at the one-year follow-up. ${ }^{11}$ A study comparing FBT with family systems therapy (SyFT) found that both groups had similar rates of remission in eating disorder symptomatology. ${ }^{12}$ However, compared to patients in the SyFT group, the FBT group had significantly faster weight gain early in treatment, significantly fewer days in the hospital, and lower treatment costs per patient at the end of treatment. ${ }^{12}$

\section{BCH ED Inpatient Care: Treatment as Usual (TAU)}

Traditionally, during the inpatient admission, AYAM doctors are responsible for medical stabilization and work with nutrition, nursing, and psychiatry staff to determine specific protocols and behavioral plans (see Figure 1 for a flowchart of medical hospitalization). Within 24 hours of admission, the PCS is consulted, and a full psychiatric evaluation is conducted. Nutrition staff is also consulted to assess nutritional status and develop caloric goals for each patient. Previously the focus of the treatment team was solely on medical stabilization, brief coping strategies for patients, and aftercare planning. Depending on the severity of psychiatric symptoms and malnutrition, the disposition recommendation may be a higher level of care (HLOC), including a residential treatment center, a partial hospital day program,

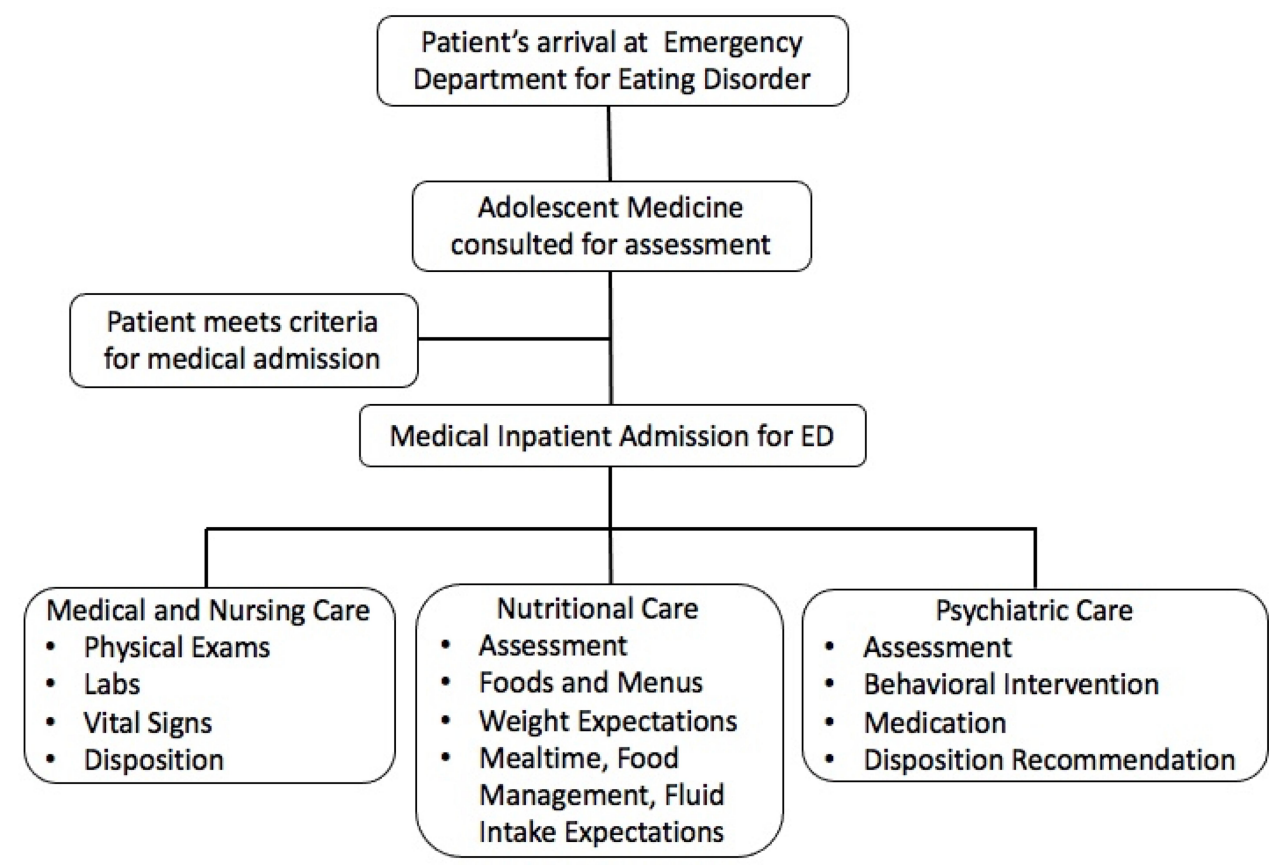

Figure I Flowchart of patients' medical hospitalization. 
or an intensive outpatient program. Upon discharge, the family would receive a meal plan and the outpatient treatment program would oversee the patient's recovery, rather than the family. There are no randomized control trials to suggest that residential treatment and outpatient partial day programs are more effective for adolescents with restrictive eating disorders than empirically based outpatient treatment. ${ }^{7,13}$ This has resulted in a philosophical shift with the preference being to refer to the least restrictive level of care to keep younger patients at home with their families. ${ }^{13}$

\section{FBT: Overview}

FBT is designed to empower families to address and reverse the factors maintaining the ED. FBT is collaborative and utilizes the family as active participants in the restoration of the patient's weight, physical health, and normalization of eating. Treatment goals include preventing hospitalization, restoring their child's weight, and returning them to their appropriate adolescent developmental phase. Families are integral to the treatment and are viewed as agents of change. ${ }^{14}$

Initially, parents are temporarily put in charge of the weight restoration process until their child can make appropriate decisions about eating. Once the ED symptoms improve, control is gradually returned to the child. FBT employs a pragmatic approach with a behavioral focus on symptom reduction. FBT takes a non-blaming stance and an agnostic view of the illness, meaning that it does not focus on the etiology of the illness. ${ }^{14}$ Therefore, families are not to blame for the ED; the ED is to be understood as a complex biological, physical, and psychological illness. The therapeutic stance of the team is "consultive" and collaborative and is one of joining with the family. ${ }^{14}$ Parents are coached by their clinical team to focus on the symptoms of the eating disorder along with the urgent need to reverse the lifethreatening weight loss and restrictive eating. FBT uses externalization strategies that are designed to help parents create a non-blaming stance towards their child which also serves to reduce stress during mealtimes. ${ }^{14}$ Externalization strategies are designed to help parents understand that their child is not in control of the ED and cannot just choose to stop the related ED behaviors. In addition to lowering family distress, externalization strategies serve to reduce parental blame and criticism towards their child, which has been shown to negatively impact treatment outcome. ${ }^{15}$ See Table 1 describing the three phases and tasks of FBT outpatient treatment.

\section{FBT: Adapting the Inpatient ED Treatment Model}

Integrating FBT in the inpatient unit is a paradigm shift from traditional practice. In order to incorporate FBT into the ongoing care of patients with restrictive eating disorders at $\mathrm{BCH}$, clinical staff from the Departments of AYAM, Psychiatry, Nutrition and Nursing met regularly to plan program changes. The FBT-trained AYAM psychologist provided in-house FBT training designed to educate clinical staff.

In the spirit of integrating FBT principles into the protocol for the medical hospitalization, the treatment team reviews the appropriateness of FBT for each patient during

Table I Phases and Related Goals of Family-Based Treatment (FBT) Outpatient Treatment

\begin{tabular}{|l|l|l|l|l|l|}
\hline \multirow{2}{*}{} & \multicolumn{5}{|c|}{ FBT Core Principles and Treatment Progression: Outpatient } \\
\cline { 2 - 7 } & $\begin{array}{l}\text { Initial } \\
\text { Symptom } \\
\text { Focus }\end{array}$ & $\begin{array}{l}\text { Agnostic View } \\
\text { of Illness }\end{array}$ & $\begin{array}{l}\text { Family Responsible for Weight } \\
\text { Restoration and Cessation of } \\
\text { Behaviors }\end{array}$ & $\begin{array}{l}\text { Non-Authoritarian } \\
\text { Stance }\end{array}$ & $\begin{array}{l}\text { Externalization of } \\
\text { Illness }\end{array}$ \\
\hline $\begin{array}{l}\text { Phase I } \\
\text { Sessions } \\
\text { I-10 }\end{array}$ & $\begin{array}{l}\text { Weight } \\
\text { restoration and } \\
\text { behavioral change } \\
\text { Weekly sessions }\end{array}$ & $\begin{array}{l}\text { Etiology not } \\
\text { discussed } \\
\text { Individual not } \\
\text { blamed for ED }\end{array}$ & $\begin{array}{l}\text { Family is the expert of their child } \\
\text { and will restore their child to } \\
\text { health }\end{array}$ & $\begin{array}{l}\text { Parents remain } \\
\text { agnostic, non-blaming } \\
\text { and supportive }\end{array}$ & $\begin{array}{l}\text { Parents learn the ED is in } \\
\text { control of their child's } \\
\text { behaviors }\end{array}$ \\
\hline $\begin{array}{l}\text { Phase 2 } \\
\text { Sessions } \\
\text { II-16 }\end{array}$ & $\begin{array}{l}\text { Stabilization or } \\
\text { continued weight } \\
\text { restoration } \\
\text { Bi-weekly sessions }\end{array}$ & $\begin{array}{l}\text { Causality not the } \\
\text { focus of treatment }\end{array}$ & $\begin{array}{l}\text { Individual is 90-95\% weight } \\
\text { restored }\end{array}$ & $\begin{array}{l}\text { Gradual control of } \\
\text { eating is returned to } \\
\text { the individual }\end{array}$ & $\begin{array}{l}\text { Individual may return to } \\
\text { activities: ED behaviors } \\
\text { are eliminated }\end{array}$ \\
\hline $\begin{array}{l}\text { Phase } 3 \\
\text { Sessions } \\
\text { I7-20 }\end{array}$ & $\begin{array}{l}\text { Maintenance } \\
\text { Monthly sessions }\end{array}$ & $\begin{array}{l}\text { Other comorbid } \\
\text { problems may be } \\
\text { discussed }\end{array}$ & $\begin{array}{l}\text { Individual can eat without engaging } \\
\text { in ED behaviors }\end{array}$ & $\begin{array}{l}\text { Identify relapse } \\
\text { prevention strategies }\end{array}$ & $\begin{array}{l}\text { Individual can navigate age- } \\
\text { appropriate challenges }\end{array}$ \\
\hline
\end{tabular}


the hospitalization - this discussion involves the assessment of patient symptomology, appropriate level of care, and parent availability to monitor their child upon discharge. The treatment team reviews treatment approaches with the family to assess if they prefer outpatient treatment or residential, and to determine if one parent is available to prepare and monitor all meals, and if the family can access a FBT provider either at the AYAM outpatient clinic or in their community. If the team and family determine that FBT is feasible, the treatment philosophy is introduced to parents.

First, the adolescent medicine and psychiatry staff provide psychoeducation about eating disorders to parents so they can understand the complex nature of the illness. The treatment team begins the process of "externalizing" the eating disorder, while the dieticians support parents to oversee their child's food selection. Therefore, the process of empowering parents by putting them in charge of their child's food selection starts immediately. The goal is for parents to integrate the FBT tenets that "food is medicine" and that they need to be in control of their child's nutrition because their child is too impaired by the ED to choose appropriate food items. ${ }^{14}$ This shift is particularly important at this initial stage of treatment as this puts the parents back in charge of their child's health and food as most parents were before the ED. See Table 2 describing the integration of FBT principles into the inpatient stay.

Because of the significant health risks of their child's illness, parents are supported by the treatment team and are encouraged to make decisions designed to effectively treat their child's ED. The team coaches parents to tolerate their child's distress at meal times and normalizes the intensity of their emotions as part of the process of nutritional rehabilitation. The PCS team may provide the patient with strategies to tolerate physical discomfort, but their main task is to help parents understand the ED as a complex egosyntonic illness that has impacted their child's ability to make logical decisions regarding their food intake and disordered behaviors. This discussion is designed to reinforce a non-blaming stance towards their child and themselves. If families opt to continue FBT on an outpatient basis, the AYAM psychologist meets with parents to provide information about continuing FBT treatment in the AYAM outpatient clinic upon discharge. There are various reasons why families may choose not to pursue outpatient FBT: geographical location, family stressors, demanding work schedules, or personal reasons.

\section{FBT Nutrition Model}

The nutrition staff redesigned the protocols and menu to align more closely with FBT tenets. The dietitian meets with the family on the first day of admission to obtain full nutrition history. At this time, if FBT has been determined to be an appropriate course of treatment, parents are encouraged to select meals for their child. This begins the process of parental control over mealtimes, and thereby removes the patient's inner conflict about foods they will or will not consume. When successful, parents choose daily meals outside the room and the patient is not informed of the meal choice. This serves to prevent the patient from perseverating over choosing the meals. The goal is to begin a pattern where the patient will trust the parents to make appropriate choices so that the patient feels comfortable with their parent continuing this process at home. The meals are supervised by inpatient staff and parents are encouraged to learn how to supervise meals by validating their child along with interrupting disordered eating behaviors. The inpatient medical unit

Table 2 Phases and Related Goals of Family-Based Treatment (FBT) Inpatient Treatment

\begin{tabular}{|c|c|c|c|c|}
\hline \multicolumn{5}{|c|}{ FBT Core Principles Applied to the Inpatient Admission } \\
\hline Agnostic View of Illness & $\begin{array}{l}\text { Initial } \\
\text { Symptom } \\
\text { Focus }\end{array}$ & $\begin{array}{l}\text { Increase Parental Self- } \\
\text { Efficacy and } \\
\text { Empowerment }\end{array}$ & $\begin{array}{l}\text { Non-Authoritarian } \\
\text { Stance }\end{array}$ & Externalization of IIIness \\
\hline $\begin{array}{l}\text { Treatment team models a non- } \\
\text { blaming stance } \\
\text { Etiology of illness is not } \\
\text { discussed } \\
\text { EDs are viewed as complex } \\
\text { multifactorial illnesses - } \\
\text { psychoeducation is offered } \\
\text { Staff minimizes parent guilt and } \\
\text { shame }\end{array}$ & $\begin{array}{l}\text { Daily weight } \\
\text { restoration is } \\
\text { the focus } \\
\text { ED behaviors } \\
\text { are targeted } \\
\text { Team models } \\
\text { limit setting } \\
\text { Medical } \\
\text { stability is } \\
\text { achieved }\end{array}$ & $\begin{array}{l}\text { Parents are encouraged and } \\
\text { validated by staff } \\
\text { Parents choose meals } \\
\text { Parents sit with their child } \\
\text { during meals and learn meal } \\
\text { coaching from staff } \\
\text { Parents identify supports } \\
\text { during meals: eg siblings }\end{array}$ & $\begin{array}{l}\text { Treatment team works in } \\
\text { close collaboration with } \\
\text { parents } \\
\text { Parents are seen as } \\
\text { experts of their child } \\
\text { Treatment team problem } \\
\text { solves with parents re: } \\
\text { upcoming challenges }\end{array}$ & $\begin{array}{l}\text { Treatment team models } \\
\text { externalization strategies - } \\
\text { child and ED are separate } \\
\text { Staff supports family with } \\
\text { these strategies to reduce } \\
\text { conflict } \\
\text { Parents learn to minimize } \\
\text { emotional reactions to } \\
\text { behaviors during meals }\end{array}$ \\
\hline
\end{tabular}


uses predesigned, color-coded meal plans that consist of 4-5 whole meal options that is to be selected by patient (if over 17 years old) or parent (if patient is 17 years old or younger). If a patient is over 17 and the family chooses to employ a FBT approach, then the parents will be given the menus.

\section{FBT Implementation Challenges}

Initiating FBT within the inpatient setting has challenges. The most common challenge is the parent's anxiety of taking autonomy from their child. Losing control over their food and bodies, in conjunction with an unwanted hospital stay, is usually upsetting for someone with an ED. Parents are often overwhelmed by the ED and feel they do not know how to feed their child after weeks or months of battling their child's illness. Parents often want the treatment team to make decisions and feel anxious about upsetting their child. Putting parents in charge of the meals and helping them to tolerate their child's distress may initially increase parental stress levels, however, when parents are coached to understand and externalize their child's symptoms, this may empower parents and support them to continue the meal monitoring at home. When parents understand the importance of starting FBT during the inpatient stay, thus begins the process of empowering parents to restore their child to health.

\section{Conclusions}

Although there are many obstacles when making changes to medical and psychiatric ED protocols in a large institution, evidence has begun to show that initiating FBT during hospitalization is likely to demonstrate better outcomes. ${ }^{16}$ Initiation of FBT during hospitalization may have better outcomes than those who choose other treatment options; however, further study is needed. We are limited in our conclusions as we did not collect pre- and post-data regarding patient outcomes in families who chose to utilize FBT tenets. Other research has shown preliminary support for offering components of FBT during an acute medical hospital stay - participants in the FBT group required fewer medical readmissions and achieved higher target goal weights than the participants in the TAU group. ${ }^{16}$ As noted, more research is needed to demonstrate that providing the implementation of FBT principles in a medical inpatient unit will improve treatment outcomes for adolescents with restrictive EDs. ED patients are acutely ill, and hospitalization is stressful for both patient and family. The inclusion of FBT principles into $\mathrm{BCH}$ inpatient medical protocol achieves the goal of offering a more family-centered approach while integrating components of what is currently "best practice" for adolescents with restrictive eating disorders. ${ }^{1,7,13}$

\section{Disclosure}

Melissa Freizinger, Lisa Mancini, Emily Pluhar, and Grace Jhe are all affiliated with the Department of Adolescent and Young Adult Medicine (AYAM) at Boston Children's Hospital. The authors report no other conflicts of interest in this work.

\section{References}

1. Golden NH, Katzman DK, Sawyer, SM, et al.; Society for Adolescent Health and Medicine. Position Paper of the Society for Adolescent Health and Medicine: medical management of restrictive eating disorders in adolescents and young adults. J Adolesc Health. 2015;56 (1):121-125. doi:10.1016/j.jadohealth.2014.10.259.

2. Toulany A, Wong M, Katzman DK, et al. Cost analysis of inpatient treatment of anorexia nervosa in adolescents: hospital and caregiver perspectives. CMAJ Open. 2015;3(2):E192-E197. doi:10.9778/ cmajo. 20140086

3. Zabala MJ, Macdonald P, Treasure J. Appraisal of caregiving burden, expressed emotion and psychological distress in families of people with eating disorders: a systematic review. Eur Eat Disord Rev. 2009;17(5):338-349. doi:10.1002/erv.925

4. Eisler I, Dare C, Russell GF, Szmukler G, le Grange D, Dodge E. Family and individual therapy in anorexia nervosa. A 5-year follow-up. Arch Gen Psychiatry. 1997;54(11):1025-1030. doi:10.1001/archpsyc.1997.01830230063008

5. American Psychiatric Association Work Group on Eating Disorders. Practice guideline for the treatment of patients with eating disorders (revision). Am $J$ Psychiatry. 2000;157(1Suppl):1-39. PMID: 10642782 .

6. National Collaborating Centre for Mental Health (UK). Eating Disorders: Core Interventions in the Treatment and Management of Anorexia Nervosa, Bulimia Nervosa and Related Eating Disorders. Leicester (UK): British Psychological Society (UK); 2004.

7. Lock J. Updates on treatments for adolescent anorexia nervosa. Child Adolesc Psychiatr Clin N Am. 2019;28(4):523-535. doi:10.1016/j. chc.2019.05.001

8. Hoste RR. Incorporating family-based therapy principles into a partial hospitalization programme for adolescents with anorexia nervosa: challenges and considerations. J Fam Ther. 2015;37 (1):41-60. doi:10.1111/joft.2015.37.issue-1

9. Murray SB, Anderson LK, Rockwell R, Griffiths S, Le Grange D, Kaye WH. Adapting family-based treatment for adolescent anorexia nervosa across higher levels of patient care. Eat Disord. 2015;23 (4):302-314. doi:10.1080/10640266.2015.1042317

10. Halvorsen I, Reas DL, Nilsen JV, Rø Ø. Naturalistic outcome of family-based inpatient treatment for adolescents with anorexia nervosa. Eur Eat Disord Rev. 2018;26(2):141-145. doi:10.1002/ erv. 2572

11. Lock J, Le Grange D, Agras WS, Moye A, Bryson SW, Jo B. Randomized clinical trial comparing family-based treatment with adolescent-focused individual therapy for adolescents with anorexia nervosa. Arch Gen Psychiatry. 2010;67(10):1025-1032. doi:10.1001/ archgenpsychiatry.2010.128 
12. Agras WS, Lock J, Brandt H, et al. Comparison of 2 family therapies for adolescent anorexia nervosa: a randomized parallel trial. JAMA Psychiatry. 2014;71(11):1279-1286. doi:10.1001/jamapsychiat ry.2014.1025

13. Derenne J. The role of higher levels of care for eating disorders in youth. Child Adolesc Psychiatr Clin N Am. 2019;28(4):573-582. doi:10.1016/j.chc.2019.05.006

14. Lock J, Le Grange D, Agras WS, Dare C. Treatment Manual for Anorexia Nervosa: A Family-Based Approach. New York, NY: Guildford Press; 2013.
15. Rienecke RD, Accurso EC, Lock J, Le Grange D. Expressed emotion, family functioning, and treatment outcome for adolescents with anorexia nervosa. Eur Eat Disord Rev. 2016;24(1):43-51. doi:10.1002/erv.2389

16. Matthews A, Peterson CM, Peugh J, Mitan L. An intensive family-based treatment guided intervention for medically hospitalized youth with anorexia nervosa: parental self-efficacy and weight-related outcomes. Eur Eat Disord Rev. 2019;27(1):67-75. doi:10.1002/erv.2632

\section{Publish your work in this journal}

Psychology Research and Behavior Management is an international, peer-reviewed, open access journal focusing on the science of psychology and its application in behavior management to develop improved outcomes in the clinical, educational, sports and business arenas. Specific topics covered in the journal include: Neuroscience, memory and decision making; Behavior modification and management; Clinical applications; Business and sports performance management; Social and developmental studies; Animal studies. The manuscript management system is completely online and includes a very quick and fair peer-review system, which is all easy to use. Visit http://www. dovepress.com/testimonials.php to read real quotes from published authors. 